\title{
Thyroid surgery with a harmonic scalpel: an experimental study
}

This article was published in the following Dove Press journal:

Medical Devices: Evidence and Research

II June 2016

Number of times this article has been viewed

\author{
Didier Dequanter' \\ Martin Lammens ${ }^{2}$ \\ Nathalie Nagy' \\ Mohammad Shahla' \\ Yasmine Deniz' \\ Christine Aubert' \\ Youri Vanhemelrijck' \\ Philippe Lothaire' \\ 'Department of Head and Neck \\ Surgery, Centre Hospitalier \\ Universitaire Charleroi, Charleroi, \\ 2Department of Pathology, \\ Universitair Ziekenhuis Antwerpen, \\ Antwerp, Belgium
}

Background: The goal of the study was to determinate the safety of the harmonic scalpel, widely used in thyroidectomy, near the recurrent laryngeal nerve (RLN).

Methods: The study involved ten pigs of either sex. Twenty RLNs at risk were dissected using the new harmonic scalpel FOCUS. The distances between the nerve and the activated instrument were checked with a millimeter ruler. After dissection, the pigs were euthanized, and both RLNs were fixed in formol and examined by histology after staining with hematoxylin-eosin. Due to technical reasons, only 18 RLNs from the ten pigs could be examined.

Results: In the experiment that investigated the extent of heat injury, ultrasonic dissection did not cause any immediate damage of the nerve even close to the RLN ( $1 \mathrm{~mm}$ away from the RLN). Conclusion: The use of harmonic scalpel FOCUS for thyroid surgery is safe for the surrounding structures (nerves). Careful tissue applications of the device near the RLN (1 mm) did not cause any lesion histologically.

Keywords: harmonic scalpel, recurrent laryngeal nerve, thyroid surgery

\section{Introduction}

For many thyroid disorders, operative resection is the treatment of choice. Meticulous hemostasis is one of the first priorities of thyroid surgeons to prevent potential complications. ${ }^{1-3}$ Harmonic scalpel is an innovative hemostatic device designed as an alternative to conventional techniques, which offers adequate hemostasis with minimal thermal spread. ${ }^{1-10}$

However, even if ultrasonic (US) devices are used widely around the world, the extent to which the use of US scalpel is safe adjacent to the surrounding structures, especially around the recurrent laryngeal nerve (RLN), in thyroid surgery remains unclear.

The aim of the study was to determine the safety of harmonic scalpel FOCUS (Ethicon Endosurgery, part of the Johnson \& Johnson family of companies New Brunswick, NJ, USA) and its use close to the RLN in an animal model.

\section{Methods}

The study involved ten pigs of either sex (mean age 3 years; mean weight $56 \mathrm{~kg}$ ). Twenty RLNs at risk were dissected and harmonic scalpel FOCUS was used near the RLN.

The distances between the nerve and the activated instrument were checked with a millimeter ruler. After dissection, the pigs were euthanized and both RLNs were
Correspondence: Didier Dequanter Department of Head and Neck Surgery, Centre Hospitalier Universitaire Charleroi, Maandal, 6, 1652 Alsemberg, Belgium

Email: didier.dequanter@pandora.be 
fixed in formol and examined by histology after staining with hematoxylin-eosin. Due to technical reasons including improper storage of the specimen, only 18 RLNs from the ten pigs could be examined.

General anesthetic protocol was identical for the animals. Each animal was fasted for 12 hours and received an intramuscular injection of a mixture comprising $1.5+1.5$ $\mathrm{mL}$ of arepromazine ${ }^{\circledR}$ (Kela Lab, Hoogstraten, Belgium) butorphanol ${ }^{\circledR}$ (Mylan, Hatfield, UK) $+7+7 \mathrm{~mL}$ of atropine ${ }^{\circledR}$ (Aguettant, Lyon, France) ketamine ${ }^{\circledR}$ (Pfizer, Inc., New York, NY, USA). This allows adequate conditioning of the animals and moving them under safe conditions to the operating room. After locating a peripheral vein at the jugular level, induction of general anesthesia was achieved by intravenous injection of somnotol ${ }^{\circledR}$ (Biomeda, Canada) at a dose of 10 $\mathrm{mg} / \mathrm{kg}$ after an intravenous bolus of $10 \mathrm{~mL}$. After establishment of an endotracheal tube of diameter $8 \mathrm{~mm}$, the animal was mechanically ventilated using a respirator. Anesthesia was maintained with the gas $2 \%$ isoflurane ${ }^{\circledR}$ (Piramal Critical Care, Bethlehem, PA, USA). The tube was carefully placed at the glottis level, placing the electrodes between the vocal cords. The electrodes were placed on the endotracheal tube before intubation and were connected with the used device (Neurosign 100; Magstim, Withland, UK) and a bipolar stimulator. No neuromuscular blocking agent was used during the procedure.

Loss of signal was defined by an electromyography (EMG) change from initial satisfactory waveform and/or the absence or low response $(100 \mu \mathrm{V})$ with stimulation at $0.5 \mathrm{~mA}$ in a dry field.

The study was approved by the local institutional review board of the Centre Hospitalier Universitaire of Charleroi. They confirmed that all experiments were performed following the regulations of the Animals (Scientific Procedures) Act 1986 and the revised legislation which came into force on January 1st, 2013.

\section{Results}

None of the pigs died during induction of anesthesia. The US scalpel was easy to handle during the dissection. Measurement of EMG potentials after longitudinal dissection at different distances $(5,4,3,2$, and $1 \mathrm{~mm}$ away from the RLN) showed that no nerves were damaged, as illustrated by any change observed in the vocal muscle EMG data, while using the US device. The intraoperative EMG (amplitude and latency, respectively) showed no difference of the RLN registered before and after the dissection ( $P=0.64$ and $P=0.70$, respectively). The median amplitude value before dissection was 0.6585 (95\% confidence interval

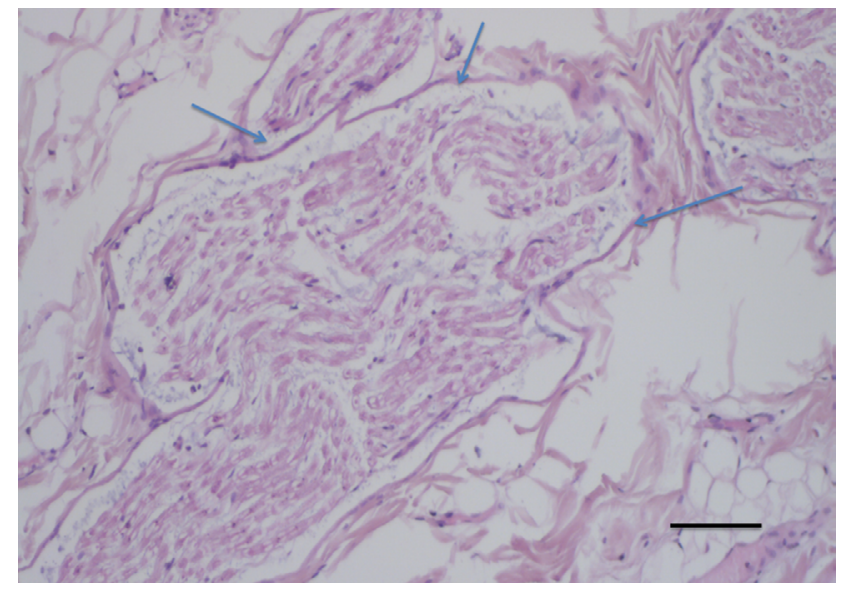

Figure I Hematoxylin and eosin staining showed all damage of the nerve, even damage close to (I mm away from) the recurrent laryngeal nerve (arrows). Note: Scale bar $=50 \mu \mathrm{m}$.

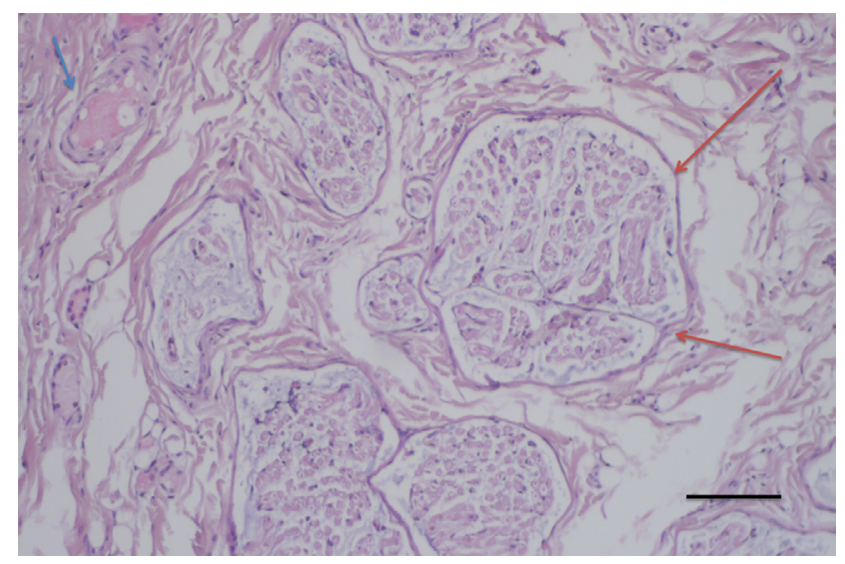

Figure 2 Some coagulation damage (blue arrow) of the surrounding fat and collagenous tissue, which in one instance was within a distance of $\sim 100 \mu \mathrm{m}$ of the nerve fascicle, without causing damage to the nerve fascicle (red arrows). Notes: Hematoxylin and eosin staining was used. Scale bar $=50 \mu \mathrm{m}$.

for the median 0.5345-0.9900) and the median amplitude after dissection was 0.6015 (95\% confidence interval for the median 0.5208-0.6933). The US scalpel was used each time in the same manner. The duration of heat exposure was the same in each dissection ( 3 seconds). A power level of 3 was always chosen for both cutting and coagulation because the US scalpel is usually set at a power level of 3 when used in thyroidectomy.

Concerning the morphological results, there was no nerve fiber damage observed after US nerve sheath dissection. In the experiment that investigated the extent of heat injury, US dissection did not cause any damage of the nerve even close to the RLN (1 mm away from the RLN) (Figure 1). There was some coagulation damage of the surrounding fat and collagenous tissue, which in one instance reached approximately $100 \mu \mathrm{m}$ of the nerve fascicles (Figure 2), without damage to the latter. 


\section{Discussion}

In sutureless open thyroid surgery and endoscopic thyroid surgery, ${ }^{11}$ the operating space is limited and maintaining a bloodless operating space is, therefore, essential. The US scalpel is a device of choice for such procedures and is mainly used. However, inappropriate use of this device may harm vital structures such as nerves.

RLN injury is a serious complication in thyroidectomy. The cause of injury may be traction or transection of the nerve during surgery. ${ }^{12}$ Thermal injury of the operating device is another major potential cause of RLN injury. According to the reports of Owaki et $\mathrm{al}^{10}$ and Koh et al, ${ }^{14}$ temporary RLN paralysis after thyroidectomy may be related to the thermal injury caused by the US scalpel.

In order to determine the safety margin for US dissection close to the nerves, we tested US dissection close to the RLN dissected during thyroid surgery in pigs. The functional and morphological results did not show any damage to the dissected nerves.

In their study, Carlander et $\mathrm{al}^{2}$ confirmed that ultrasonically activated instruments were safe for dissection close to the nerves. Their study involved 37 rats. Each sciatic nerve was exposed by separation of biceps femoris and tensor fascia lata. By using US scissors, no nerve dysfunction was observed.

Our functional and morphological results supported the results reported by Kirdak et al ${ }^{15}$ and Bertke et al. ${ }^{16}$ Using the same device, they performed thyroidectomy consecutively in 65 patients. There was no permanent RLN palsy observed. The incidence of temporary RLN injury was 3.3\%, which was lower than that in the conventional group.

Moreover, Markogiannakis et al, ${ }^{13}$ in their prospective study, evaluated the safety and clinical effectiveness of US dissection in thyroid surgery. They concluded, like other authors, ${ }^{14,15}$ that US scalpel can be used safely in thyroid surgery with no increase in complication rate. They required a safety margin of 3-5 $\mathrm{mm}$ between the active curved blade and the structures. The device should be placed in such a manner that the inactive blade is closer to the surrounding structures, and the shears should always be used on a lower power setting and with short activation times $(<10$ seconds).

We demonstrated histologically, with these precautions, that US dissection can be used safely closer to the surrounding structures (RLN) in thyroid surgery.

In the same way, in order to determine the extent to which the use of US scalpel adjacent to the RLN could affect this nerve, Jiang et $\mathrm{ll}^{12}$ used a rabbit model to determine the safety margin of US scalpel application. They concluded that if it is used around the RLN at a power level of 3 , the activated US scalpel tip should be $>2 \mathrm{~mm}$ from the nerve and the duration of incision should be $<3$ seconds.

In our experience, we did not observe any lesion when the activated US scalpel tip was used near the RLN (1 mm) at a power level of 3 during an activation time of 5 seconds.

Moreover, recently, Revelli et al ${ }^{17}$ confirmed the safety of total thyroidectomy performed using harmonic scalpel FOCUS and reported that the rate of hypocalcemia could be reduced.

\section{Conclusion}

The use of US dissection for thyroid surgery is safe for the surrounding structures (nerves). Careful tissue applications of the device near the RLN (1 mm) did not cause any lesion histologically.

\section{Disclosure}

The authors report no conflicts of interest in this work.

\section{References}

1. Amaral JF. Laparoscopic application of an ultrasonically activated scalpel. Gastrointest Clin North Am. 1993;3:381-392.

2. Carlander J, Johansson K, Lindström S, Velin AK, Jiang CH, Nordborg C. Comparison of experimental nerve injury caused by ultrasonically activated scalpel and electrosurgery. Br J Surg. 2005;92:772-777.

3. Reeve T, Thompson NW. Complications of thyroid surgery: how to avoid them, how to manage them, and observations on their possible effect on the whole patient. World J Surg. 2000;24:971-975.

4. Tessema B, Roark RM, Pitman MJ, Weissbrod P, Sharma S, Schaefer $\mathrm{SD}$. Observations of recurrent laryngeal nerve injury and recovery using a rat model. Laryngoscope. 2009;119:1644-1651.

5. Kinoshita T, Kanehira E, Omura K, Kawakami K, Watanabe Y. Experimental study on heat production by a $23.5-\mathrm{kHz}$ ultrasonically activated device for endoscopic surgery. Surg Endosc. 1999; 13:621-625.

6. Birch DW, Park A, Shuhaibar H. Acute thermal injury to the canine jejunal free flap: electrocautery versus ultrasonic dissection. Am Surg. 1999;65:334-337.

7. Amaral JF. The experimental development of an ultrasonically activated scalpel for laparoscopic use. Surg Laparosc Endosc. 1994;4:92-99.

8. Koch C, Friedrich T, Metternich F, Tannapfel A, Reimann H-P, Eichfeld U. Determination of temperature elevation in tissue during the application of the harmonic scalpel. Ultrasound Med Biol. 2003;29:301-309.

9. Quah HM, Jayne DG, Eu KW, Seow-Choen F. Bladder and sexual dysfunction following laparoscopically assisted and conventional open mesorectal resection for cancer. Br J Surg. 2002;89:1551-1556.

10. Owaki T, Nakano S, Arimura K, Aikou T. The ultrasonic coagulating and cutting system injures nerve function. Endoscopy. 2002;34:575-579

11. Amaral JF. Depth of thermal injury: ultrasonically activated scalpel versus electrosurgery. Surg Endosc. 1995;9:226-231.

12. Jiang H, Shen H, Jiang D, et al. Evaluating the safety of the Harmonic scalpel around the recurrent laryngeal nerve. ANZ J Surg. 2010;80(11):822-826.

13. Markogiannakis H, Kekis PB, Memos N, et al. Thyroid surgery with the new harmonis scalpel: A prosepctive randomized study. Surgery. 2011;149(3):411-415 
14. Koh YW, Kim JW, Lee SW, Choi EC. Endoscopic thyroidectomy via a unilateral axillo-breast approach without gas insufflation for unilateral benign thyroid lesions. Surg Endosc. 2009;23:2053-2060.

15. Kirdak T, Korun N, Ozguc H. Use of Ligasure in thyroidectomy procedures: results of a prospective comparative study. World J Surg. 2005;29:771-774.
16. Bertke BD, Scoggins PJ, Welling AL, et al. Ex vivo and in vivo evaluation of an ultrasonic device for precise dissection, coagulation, and transection. Open Access Surgery. 2014;8:1-7.

17. Revelli L, Damiani G, Bianchi CB, et al. Complications in thyroid surgery: Harmonic scalpel, Harmonic focus versus conventional hemostasis: a meta-analysis. Int J Surg. 2016;(Suppl 1):S22-S32.

\section{Publish your work in this journal}

Medical Devices: Evidence and Research is an international, peerreviewed, open access journal that focuses on the evidence, technology, research, and expert opinion supporting the use and application of medical devices in the diagnosis, monitoring, treatment and management of clinical conditions and physiological processes. The identification of novel devices and optimal use of existing devices which will lead to improved clinical outcomes and more effective patient management and safety is a key feature. The manuscript management system is completely online and includes a quick and fair peer-review system. Visit http://www. dovepress.com/testimonials.php to read real quotes from authors.

Submit your manuscript here: https://www.dovepress.com/medical-devices-evidence-and-research-journal 